\title{
Factors associated with patient willingness to participate in anaesthesia clinical trials: a vignette-based cross-sectional study
}

\author{
Caroline Noirmain', Béatrice Gil-Wey ${ }^{1}$, Isabelle Pichon', Pauline Brindel ${ }^{2}$ and Guy Haller ${ }^{1,3^{*}}$
}

\begin{abstract}
Background: Clinical trials are essential to improve knowledge of anesthesia and perioperative medicine. Unfortunately, many studies face participant-recruitment issues and fail to include the planned number of participants. There is limited published data about how information delivered about the study or how the experiences and attitudes of prospective participants influence willingness to participate. The purpose of this study was to identify such factors in the domain of anesthesia care.
\end{abstract}

Methods: We performed a cross-sectional study at the Geneva University Hospitals (Switzerland) using a newly developed paper-based questionnaire on a sample of outpatients with a recent hospital stay and that were aged over 18 years, confident speaking French and free of any disease that could hinder participation. We explored patient personal factors, such as current health, past exposure to clinical research and anesthesia, as well as study-related factors. Six different scenarios for clinical studies were assessed. Linear regression modeling was used to assess the specific association between personal and study-related factors and willingness to participate in the studies described in the scenarios.

Results: On the 1318 eligible patients, 398 fully completed the questionnaire. Multivariable adjustment revealed that factors related to altruistic values $(\beta, 9.6,95 \% \mathrm{Cl} 3.4$ to $15.7, P=0.002)$, to the feeling of benefiting from a more effective treatment $(\beta, 4.7,95 \% \mathrm{Cl} 0.2$ to $9.2, P=0.041)$ and to the absence of fear about double blinding $(\beta, 5.7,95 \% \mathrm{Cl} 1.3$ to $10.2, P=0.012)$ were positively associated with willingness to participate. Conversely, concerns about drug-related adverse effects $(\beta,-11.7$, $95 \% \mathrm{Cl}-16.9$ to $-6.5, P<0.001)$ and anxiety about surgery $(\beta,-5.2,95 \% \mathrm{Cl}-10.0$ to $-0.5, P=0.031)$ were negatively associated with willingness to participate.

Conclusion: Our study was based on vignettes illustrating typical scenarios of clinical trials performed in anesthesia. However, their similarities with real studies still remains hypothetical and our results should be interpreted as such. Nevertheless, the study contributes to improve understanding of factors that may act as incentives or barriers to participation in clinical trials. It highlights the importance of providing appropriate information and reassurance to patients.

Keywords: Anesthesia, Clinical trials, Willingness to participate, reasons for refusal

\footnotetext{
* Correspondence: guy.haller@hcuge.ch

'Division of Anesthesia, Department of Acute Care Medicine, Geneva

University Hospitals and Faculty of Medicine University of Geneva, Rue

Perret-Gentil 4, Geneva, Switzerland

${ }^{3}$ Health Services Management and Research Unit, Department of

Epidemiology and Preventive Medicine, Monash University, The Alfred

Centre, 99 Commercial Road, Melbourne Vic 3004, Australia

Full list of author information is available at the end of the article
}

(c) The Author(s). 2020 Open Access This article is licensed under a Creative Commons Attribution 4.0 International License, which permits use, sharing, adaptation, distribution and reproduction in any medium or format, as long as you give appropriate credit to the original author(s) and the source, provide a link to the Creative Commons licence, and indicate if changes were made. The images or other third party material in this article are included in the article's Creative Commons licence, unless indicated otherwise in a credit line to the material. If material is not included in the article's Creative Commons licence and your intended use is not permitted by statutory regulation or exceeds the permitted use, you will need to obtain permission directly from the copyright holder. To view a copy of this licence, visit http://creativecommons.org/licenses/by/4.0/ The Creative Commons Public Domain Dedication waiver (http://creativecommons.org/publicdomain/zero/1.0/) applies to the data made available in this article, unless otherwise stated in a credit line to the data. 


\section{Background}

Clinical trials inform clinical practice and contribute to its improvement [1]. However, numerous clinical trials are not published because they fail to recruit the planned number of participants $[2,3]$. A recent publication revealed that more than $17.2 \%$ of the clinical trials accepted by Ethics Committees had been abandoned [4]. A study conducted in the United Kingdom revealed that only 31\% of approved clinical trials had completed participant recruitment on time and with the planned number of participants [5]. In $42 \%$ of the clinical trials, the number of participants had to be modified, resulting in sample number reduction for most studies and, thus, a loss of study power. Finally, it was also demonstrated that $54 \%$ of trials had an unplanned extension of the duration of the study, resulting in increased study costs [5].

A lack of rigor in managing and finalizing clinical research projects is often attributed to participant recruitment issues [6]. Several factors negatively influencing willingness to participate have previously been identified, including patient fear of side effects or of receiving a less effective treatment $[7,8]$, a poor understanding of the randomization or blinding process or of the placebo treatment principle $[9,10]$, or patient a priori preference for a specific treatment [11]. In addition, studies requiring additional testing, such as blood sampling [12], an extra visit $[13,14]$ or long commuting to the study site [15], are also less likely to recruit patients. Finally, patients can also develop distrust of study investigators and refuse to participate if they do not understand the research subject [16], develop the feeling of being a "guinea pig" [17] and fear that the treatment is beyond their control $[18,19]$. Most of these barriers to patient participation in clinical trials were identified from studies in the field of cancer medicine [20-22] or infectious disease [23, 24].

While challenges for participant recruitment are also encountered in the field of anaesthesia [7, 25], the evidence in the literature about the factors influencing participation is still limited in the field. Early studies in anesthesia performed in the United States and Canada in the context of same-day surgery demonstrated that patient participation in a clinical trial can be influenced by the timing of the first encounter with investigators [26]. It has also been shown that the use of invasive procedures (i.e., bronchoscopy, epidural catheter insertion) can significantly decrease study participation (43 to 67\%) [27, 28]. Apart from these limitations, it currently remains largely unclear which patient personal characteristics and/or study-related factors are associated with refusal or acceptance for participation in clinical trials for anesthesia. Therefore, we conducted a cross-sectional study based on a paper-based questionnaire to specifically assess the attitudes of inpatients towards anesthesia clinical trials.

\section{Methods}

\section{Design and setting}

The study was conducted between 2013 and 2014 at the Geneva University Hospitals (Switzerland) a tertiary teaching hospital network of 1835 beds that includes all specialties (pediatrics, geriatrics, psychiatrics, medicine and surgery). The protocol was approved by the Central Ethics Committee of Human Research of the Geneva University Hospitals, Switzerland (CER 12-123 - NAC 12-049). A waiver for explicit written individual consent was provided by the ethics committee for this questionnaire study.

\section{Questionnaire content and administration}

The questionnaire was developed following an extensive literature review [29-34] and meetings with experienced clinical researchers at the hospital. Their professional expertise was used to identify and classify the most meaningful factors from the literature that may hinder patient participation to clinical trials. We identified 18 personal and study-related factors likely to influence patient participation and were included in the questionnaire. Personal factors included beliefs about best care practice, altruism, previous participation in a clinical trial, level of trust in healthcare professionals, and fears of side effect from medication and procedures. We explored opinions on ways to improve medical knowledge, possible benefits of new treatments, beliefs of individual patients and overall stress associated with surgery and medication. Studyrelated factors included financial compensations for study participants, commuting to the clinical trial, blood test results, randomization, double-blinding (neither investigators nor participants are aware of the type of treatment received), and the type of "placebo" treatment used. We also assessed general knowledge and attitudes towards clinical research as well as demographic characteristics and health conditions of potential participants.

Clinical trials in anesthesia aim at optimizing the management of patient through therapeutic test or investigations. In our study, the willingness to participate in a clinical trial was assessed using six different types of scenarios related to anesthesia care and that included: 1) a new drug not currently available on the market, 2) a new dosage of a well-established medication, 3) a new indication of a current medication, 4) side effects of a well-established medication, 5) a new locoregional anesthesia technique (i.e., epidural or nerve block), and 6) a new anesthetic monitoring device (i.e., blood pressure measurement, electrocardiogram). For each proposed scenario, participants were asked about their willingness to participate to the type of study described in the context of anesthesia care.

Answers were rated on a 5-point Likert scale, including the following choices: "I would certainly accept", "I 
would probably accept", "I don't know if I would accept", "I would probably refuse", "I would certainly refuse". The final questionnaire (provided in Additional file 1) included 46 questions and was pre-tested for understanding and formatting on a convenience sample of 10 volunteers.

A random group of 1800 patients aged over 18 years, fluent in French, free of any severe disease hindering participation (i.e., cognitive disorder, severe handicap) and admitted to the Geneva University Hospitals within the three previous years was identified in the hospital administrative database and listed for the study. As the data did not allow the identification of non-eligible patients, they all received a questionnaire sent by post mail. However, the questionnaire was accompanied by an introduction letter explaining the study purpose and allowed participants to return an empty questionnaire if they felt they could not answer because: "they were not confident speaking French", "had poor health condition", "could not participate in any type of study" and "had other reason" with the space to provide comments. In addition patients who had died since their hospital stay were identified in the death registry or through contact with families.

The questionnaire was designed to protect the anonymity of the respondents. A unique ID number was assigned to each questionnaire sent. Respondents' names were only available to one research nurse in charge of mailing the questionnaires and reminders.

\section{Sample size calculation and statistical analysis}

A power calculation was performed to obtain a sample size able to detect a significant difference in the level of participation barriers according to willingness to participate in a study, with an $\alpha$ error of 0.05 and a study power of 0.90. A published study [35] in the field of oncology demonstrated that the mean and standard deviation (SD) of participation barriers scores for patients willing and unwilling to participate were $21.19 \pm 7.27$ and $23.78 \pm 7.15$, respectively. The calculated study sample of 328 participants was increased to 1800 patients accounting for non-eligibility and an expected low response rate.

For descriptive analysis of participant personal factors, we used frequencies, proportions and means with SD. The six different scenarios assessing willingness to participate in a clinical study were tested for correlations and internal consistency with Spearman correlation and Cronbach's alpha statistic. A value of Cronbach $\alpha \geq 0.7$ was considered adequate. Cronbach's alpha analysis indicated a reliability of 0.84 , corresponding to a correlation of $\sqrt{ } 0.84=0.92$ between the measured scale and the underlying factor. Moreover, our results from factor analysis indicated that one main factor was meaningful. To be retained, a factor needed to have an eigenvalue over 1. Since a single underlying dimension was identified (Table 1), the 6 scenario variables were combined into a unique standardized score. The analysis showed that a single underlying dimension could be identified, common to the 6 scenarios that were named "willingness to participate". We considered that the underlying concept of willingness to participate was continuous and that the intervals between the different answers on the Likert scale were equal. For each of the scenario a subscore was calculated, using Mean and Standard Deviation (SD). A scale from 0 to 100 was created by averaging the sum of all individual item scores, standardizing and reversing the scoring as it had negative correlations with the factor being measured. We used the following formula: $25 *(5$-score). As a result, we created a score on a continuous scale of 0 to 100 , with 100 corresponding to the highest level of willingness and 0 to the lowest level of willingness to participate to a clinical trial. "No opinion" was considered as a missing value.

To measure the association between patient personal characteristics, past exposure to clinical research, personal or study-related variables and willingness-to-participate scores, univariate analysis was performed. Differences in mean scores according to the different characteristics or reasons considered were compared using Student's t test, the Mann-Whitney-Wilcoxon test for binary factors, analysis of variance, or, for more than 2 factors, KruskallWallis test, depending on distribution. A non-parametric test for trend (Cuzick test) was applied to compare mean scores of willingness to participate across ordered groups, corresponding to levels of response to questions about personal reasons to participate and study-related factors. A $P$ value less than 0.05 was considered significant. Stepwise regression analysis was performed using a backward modeling procedure to regress the willingness-to-participate score on the reasons to participate, adjusted for patient personal characteristics and past exposure to research that

Table 1 Factorial analysis and factor loadings

\begin{tabular}{lllll}
\hline Scenarios & Factor 1 & Factor 2 & Factor 3 & Uniqueness \\
\hline $\begin{array}{l}\text { New drug not currently } \\
\text { available }\end{array}$ & 0.68 & -0.19 & 0.05 & 0.50 \\
$\begin{array}{l}\text { New dosage of a } \\
\text { well-established drug }\end{array}$ & 0.81 & -0.03 & -0.07 & 0.34 \\
$\begin{array}{l}\text { New indication of a } \\
\text { current medication }\end{array}$ & 0.82 & -0.04 & -0.08 & 0.33 \\
$\begin{array}{l}\text { New side effect of a } \\
\text { well-established drug }\end{array}$ & 0.59 & 0.15 & -0.09 & 0.63 \\
$\begin{array}{l}\text { New locoregional } \\
\text { anesthesia technique }\end{array}$ & 0.63 & 0.03 & 0.15 & 0.57 \\
$\begin{array}{l}\text { New anesthetic } \\
\text { monitoring device }\end{array}$ & 0.57 & 0.14 & 0.09 & 0.64 \\
\begin{tabular}{l} 
Eigen value \\
\hline
\end{tabular} & 2.85 & 0.08 & 0.05 & \\
\hline
\end{tabular}


were significantly associated in univariate analysis. Variables corresponding to personal reasons to participate and study-related factors were recoded as binary variables before inclusion in the model. The distribution of residuals was checked for all linear regression models. Analyses were performed using Stata 15 statistical software (StataCorp LLC, College Station, TX, USA).

\section{Results}

Figure 1 depicts the study flow chart. From the initial random list of potential recipients, 482 patients were considered as non-eligible because they were deceased $(N=116)$, had a wrong postal address, had moved abroad or were in psychiatric institution or prison $(N=$ $160)$, had health problem hindering questionnaire completion $(N=101)$, were not comfortable speaking French $(N=24)$ or had other reasons $(N=81)$. Of the 1318 remaining eligible patients, 611 returned the questionnaire (absolute contact rate 46\%) and 398 of these fully completed the questionnaire $(65 \%$ absolute cooperation rate). A total of 213 recipients either returned a blank questionnaire or expressed their unwillingness to participate. There was no evidence for a difference in gender distribution $(P=0.96)$ or an age difference for patients who declined to participate in the study compared with those who participated $(60.0 \pm 20.9$ vs $59.5 \pm 19.8$ years; $P=0.65$ ).

\section{Factor analysis results}

The inter-item correlation matrix for the six scenarios showed correlation coefficients ranging between 0.33 and 0.71. Cronbach's alpha analysis indicated a good level of internal consistency for the different scenarios $(\alpha=0.84)$. Following factor analysis, one main factor (Factor 1) appeared to be meaningful, with factor loadings for the different scenarios ranging between 0.57 and 0.82 . (Table 1). This factor was considered to describe patient willingness to participate in research as it correlated positively with all six scenarios. Uniqueness (the proportion of variance for a variable that is not explained by the different factors) was significant for scenarios referring to a study on side effects of drugs and a study evaluating a new monitoring device $(>0.6)$. Distribution of the score of willingness to participate across the six scenarios was approximately Gaussian. Mean score was $59.9 \pm 19.6$.

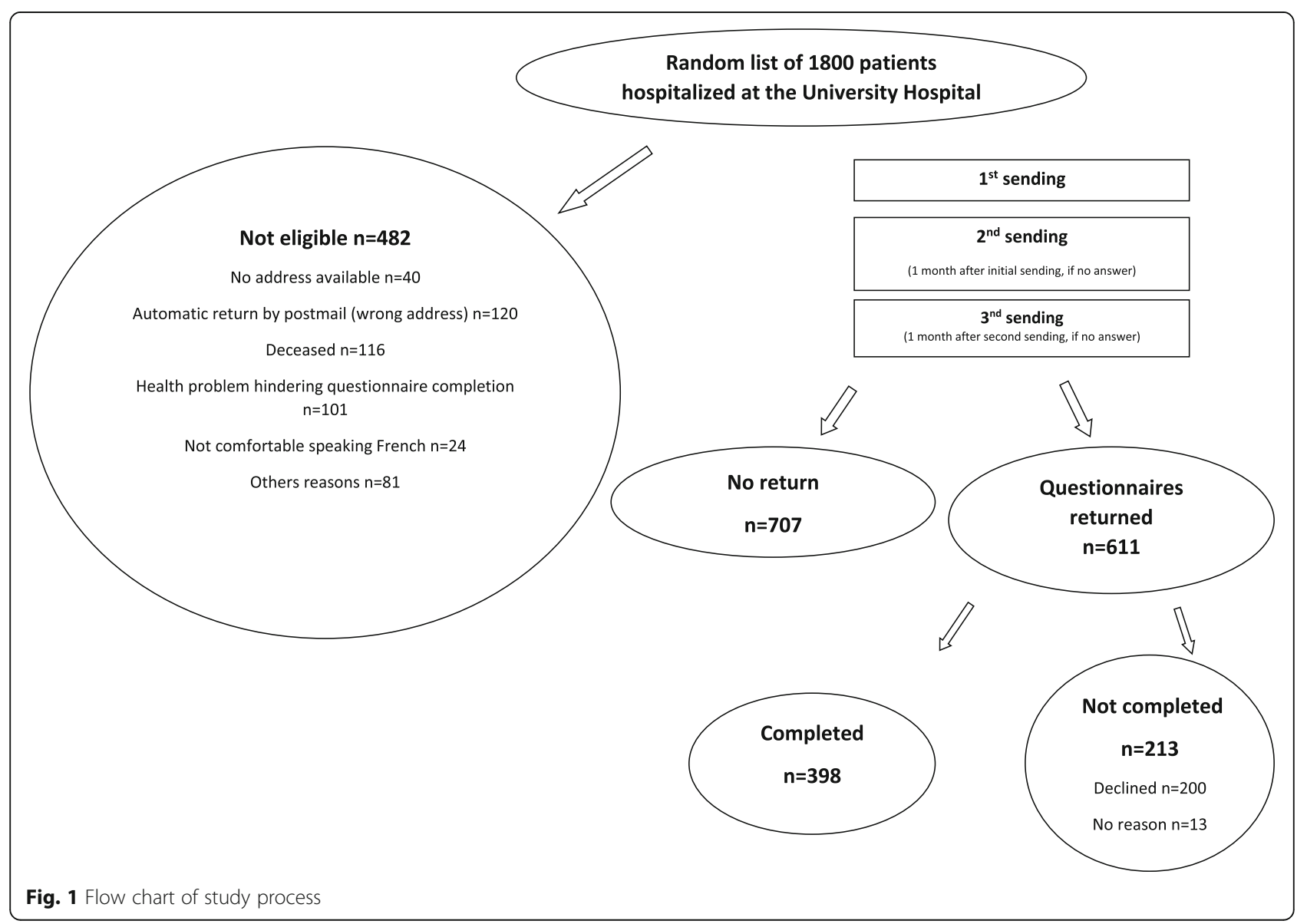




\section{Patient characteristics}

The majority of participants were female $N=208$ (54.7\%) and were aged over 59 years. A large number of participants $(40.1 \%)$ had received short cycle tertiary education or more (Table 2). Univariate analyses revealed significantly higher mean scores of willingness to participate $(P<0.05)$ for males, respondents regularly taking medications and respondents with a past experience in anesthesia and clinical research (Tables 2 and 3).

\section{Personal and study-related factors}

Table 4 summarizes the personal factors that were significantly associated with willingness to participate to clinical trials. The majority of patients exhibiting altruistic values (desire to help others or to contribute to medical progress) or with a strong perception to benefit from a more effective or better treatment, exhibited higher mean scores for willingness-to-participate (MWS) $(P<0.001)$. In contrast, lower willingness-to-participate scores were observed in a significant proportion of patients who were concerned about drug side effects (MWS $48.5 \pm 20.8$ ) or inefficacy (MWS $47.9 \pm 25.3$ ) as well as those who reported distrusted doctors (MWS $38.9 \pm 29.0$ ) (Table 4).

Study-related variables also had significant influence on willingness to participate (Table 5). Studies requiring a blood test or travel were considered as less attractive (MWS $44.3 \pm 21.5$ and $48.3 \pm 25.2$, respectively). Randomization was considered by $58.5 \%$ of the patients as a significant disincentive to participate in clinical research (MWS 50.4 \pm 22.6, $P<0.001$ ), whereas double blinding (MWS $48.5 \pm 23.8$, $P<0.001$ ) and the use of a placebo (MWS 43.2 $\pm 27.8, P<$ 0.001 ) were considered as problematic by less than half of the patients ( 44.3 and $28.8 \%$, respectively). In contrast, financial compensation for participation was significantly associated with a higher willingness to participate $(p=0.006)$.

\section{Independent personal and study-related factors predicting willingness to participate}

Personal and study-related factors were retained for the multivariable linear regression analysis of the score of willingness to participate in research and adjusted for gender, regular use of medication and past exposure to anesthesia care and clinical research. Factors that remained significant were those related to altruistic values "I could help other patients" $(P=0.02)$, "I could contribute to medical progress" $(P=0.012)$ and the expectation of benefiting from a more effective treatment $(P=0.041)$. Among other personal factors, worries about adverse events related to the drug tested $(P<0.001)$ and worries related to surgical intervention $(P=0.031)$ had a significant negative impact on the willingness to participate. The only study-related factor that was associated with willingness to participate was double blinding $(P=0.012)$ (Table 6). Patients who
Table 2 Univariate analysis for mean score of willingness to participate in a clinical study in anesthesia, according to patient characteristics

\begin{tabular}{|c|c|c|c|}
\hline Patient characteristics & N (\%) & $\begin{array}{l}\text { Mean score of } \\
\text { willingness to } \\
\text { participate } \pm \text { SD }\end{array}$ & $\boldsymbol{P}$ value \\
\hline \multicolumn{4}{|l|}{ Sex } \\
\hline Male & $172(45.3 \%)$ & $63.3 \pm 18.2$ & $0.002^{*}$ \\
\hline Female & $208(54.7 \%)$ & $57.1 \pm 20.3$ & \\
\hline \multicolumn{4}{|l|}{ Age (year) } \\
\hline$<30$ & $27(7.2 \%)$ & $60.0 \pm 17.0$ & 0.222 \\
\hline $30-39$ & $52(13.9 \%)$ & $56.3 \pm 20.0$ & \\
\hline $40-49$ & $51(13.6 \%)$ & $59.5 \pm 24.7$ & \\
\hline $50-59$ & $65(17.3 \%)$ & $60.2 \pm 17.3)$ & \\
\hline $60-69$ & $82(21.9 \%)$ & $60.1 \pm 20.9$ & \\
\hline 70-79 & $63(16.8 \%)$ & $63.1 \pm 17.5$ & \\
\hline$\geq 80$ & $35(9.3 \%)$ & $59.9 \pm 18.3$ & \\
\hline \multicolumn{4}{|l|}{ Education } \\
\hline Basic education & $44(11.8 \%)$ & $57.4 \pm 17.0$ & 0.63 \\
\hline Apprenticeship & 97 (26.1\%) & $62.8 \pm 17.8$ & \\
\hline Upper secondary education & $25(6.7 \%)$ & $60.0 \pm 18.1$ & \\
\hline Short cycle tertiary education & $72(19.4 \%)$ & $60.2 \pm 18.6$ & \\
\hline $\begin{array}{l}\text { Bachelor or higher } \\
\text { university degree }\end{array}$ & $77(20.7 \%)$ & $58.1 \pm 22.5$ & \\
\hline Other & $57(15.3 \%)$ & $59.6 \pm 22.7$ & \\
\hline \multicolumn{4}{|l|}{ Professional activity } \\
\hline Full-time employment & 71 (18.9\%) & $60.0 \pm 18.1$ & 0.42 \\
\hline Part-time employment & $64(17.1 \%)$ & $56.1 \pm 18.7$ & \\
\hline Working at home & $16(4.3 \%)$ & $60.7 \pm 22.9$ & \\
\hline Unemployed & $25(6.7 \%)$ & $64.7 \pm 23.0$ & \\
\hline Student & $11(2.9 \%)$ & $61.7 \pm 11.5$ & \\
\hline Retired or invalid & $188(50.1 \%)$ & $59.9 \pm 20.0$ & \\
\hline \multicolumn{4}{|l|}{ Working in health care } \\
\hline Yes, medical & 41 (10.9\%) & $63.1 \pm 23.2$ & 0.38 \\
\hline Yes, other & $37(9.8 \%)$ & $58.3 \pm 20.8$ & \\
\hline No & 299 (79.3\%) & $59.7 \pm 19.0$ & \\
\hline \multicolumn{4}{|l|}{ Chronic disease } \\
\hline Yes & 151 (42.5\%) & $60.8 \pm 20.7$ & 0.35 \\
\hline No & $204(57.5 \%)$ & $58.9 \pm 19.0$ & \\
\hline \multicolumn{4}{|l|}{ Taking medication } \\
\hline Yes & $258(68.8 \%)$ & $62.2 \pm 19.6$ & 0.0004 \\
\hline No & 117 (31.2\%) & $54.5 \pm 19.2$ & \\
\hline \multicolumn{4}{|l|}{ Past hospitalization } \\
\hline Yes & 367 (97.6\%) & $60.3 \pm 19.4$ & 0.25 \\
\hline No & $9(2.4 \%)$ & $52.8 \pm 18.6$ & \\
\hline
\end{tabular}

*T-test for gender, chronic disease, medication; Wilcoxon test for hospitalization and anesthesia; ANOVA for education; Kruskall Wallis test for professional activity and health sector, Chi-square test for trend for age 
Table 3 Past exposure to clinical research and mean scores for willingness to participate in a clinical trial

\begin{tabular}{llll}
\hline $\begin{array}{l}\text { Past exposure to clinical } \\
\text { research }\end{array}$ & $\mathrm{n}(\%)$ & $\begin{array}{l}\text { Mean score of } \\
\text { willingness to } \\
\text { participate } \pm \text { SD }\end{array}$ & P value \\
\hline $\begin{array}{l}\text { Have you ever been invited } \\
\text { to participate to a clinical } \\
\text { study in any medical area? }\end{array}$ & & & $0.05^{*}$ \\
$\quad$ No & $232(64.1 \%)$ & $58.1 \pm 19.9$ & \\
Yes & $130(35.9 \%)$ & $62.4 \pm 19.6$ &
\end{tabular}

Have you ever been invited to participate to $0.09^{*}$ a clinical study in the area of anesthesia care?

$\begin{array}{lll}\text { No } & 9(7.1 \%) & 50.0 \pm 24.5 \\ \text { Yes } & 117(92.9 \%) & 64.0 \pm 18.6\end{array}$

Have you ever heard about clinical research involving inpatients?

$\begin{array}{lll}\text { Yes } & 245(65.7 \%) & 61.8 \pm 20.1 \\ \text { No } & 128(34.3 \%) & 55.9 \pm 18.3\end{array}$

If yes, who informed you about clinical research involving inpatients?

$\begin{array}{lll}\text { Media } & 120(49.0 \%) & 60 \pm 20.4 \\ \text { Family } & 22(9.0 \%) & 59.5 \pm 18 \\ \text { Friends } & 35(14.3 \%) & 58.3 \pm 19.9 \\ \text { Family doctor } & 29(11.8 \%) & 67.8 \pm 15.3 \\ \text { Hospital doctor } & 117(47.8 \%) & 62.9 \pm 20.2 \\ \text { Other } & 38(15.5 \%) & 62.2 \pm 21.9\end{array}$

* Student's T-test

†P value not available, multiple answers possible for this questio

did not consider it as an issue were significantly more likely to participate.

\section{Discussion}

Assessing different kind of hypothetical scenarios of clinical trials in anesthesia, the present study identified a number of personal and study-related factors that were significantly associated with a likely willingness to participate in clinical trials for anesthesia research. Factors related to altruistic values, the expectation of beneficiating from a more effective treatment and the absence of worries about double blinding were positively associated with willingness. Conversely, concerns about adverse events related to the test drug and worries about surgery had a negative impact on willingness.

In line with a previous publication by Lobato et al. [36], we found that altruism and the feeling of contributing to the progress of science were significant incentives for patients to enroll in a clinical trial. This can be explained by the intrinsic nature of altruism, a behavior that leads to prefer benefits to third parties rather than personal advantages. Like fire-fighters who can put their own life or health in danger to help their community
[37], patients with altruistic values are more likely to accept to enroll in a clinical trial and to take the risk of testing a new medication or technique if a benefit for the community is perceived.

Another factor identified in the present study is the expectation that participating in a study is a way of improving personal fitness and benefiting from a better medical treatment. Such expectations have been reported to increase willingness to participate by 4.7 fold, and implied a feeling of benefiting from special attention if recruited in a trial [38]. Similarly, it has been shown that patients with terminal cancer favored study protocols offering curative over palliative treatments, even if the study included invasive procedures such as biopsies [39]. Patients with precarious health are therefore more likely than healthy patients to be willing to participate in clinical trials. They can perceive an additional benefit of an experimental drug over traditional therapy. Paradoxically most study tend to exclude patients with severe comorbidities, as they are expected to experience more often possible side effects of new treatments tested.

A highly significant disincentive to participation was related to inconveniences, including travel to the study site and invasive procedures such as blood-sampling. This finding is confirmed by previous studies [12, 39, 40]. Patients' perception of additional risk or pain resulting from participation to a trial had a negative impact on willingness to participate [40]. The same phenomenon has been identified in pediatric studies [41].

Concern about risk is of particular interest and constitutes a controversial aspect of study inclusions. The principle of patient autonomy, largely supported by ethics committees, enforces that potential participants have full knowledge of the risks and benefits of study participation in order to guarantee informed consent. In Switzerland, patient information is also regulated by a federal law that requires healthcare professionals to prove that they have provided enough information before any medical intervention or treatment (experimental or usual) that guarantees patient informed consent [42]. However, while disclosing an exhaustive list of all possible risks associated with a treatment (or in the case of a clinical trial, with study participation) can be considered as a recommended approach to ensure informed consent, this may also cause a lot of anxiety. Potential benefits of participation might be disregarded when patients are first presented with a long list of potential risks resulting in a high refusal rate, despite short or long term possible benefits.

Current literature suggests alternative approaches to ensure informed consent based on more personalized information processes. Mingus et al. for instance, found that patients who were approached by their own physician, who used open-ended questions and addressed 
Table 4 Personal factors and mean willingness-to-participate scores

\begin{tabular}{|c|c|c|c|c|c|c|}
\hline Personal factors influencing the willingness to participate & Strongly agreed & Agreed & Indifferent & Disagreed & Strongly disagreed & $\boldsymbol{P}$ value* \\
\hline I could receive better treatment. N (\%) & $65(18.5 \%)$ & $182(51.9 \%)$ & $52(14.8 \%)$ & $34(9.7 \%)$ & $18(5.1 \%)$ & \\
\hline Mean score \pm SD & $69.6 \pm 19.0$ & $60.9 \pm 17.6$ & $58.7 \pm 18.3$ & $56.8 \pm 21.3$ & $50.7 \pm 24.5$ & $<0.001$ \\
\hline I could help other patients. N (\%) & $110(32.5 \%)$ & $179(52.8 \%)$ & $33(9.7 \%)$ & $13(3.8 \%)$ & $4(1.2 \%)$ & \\
\hline Mean score \pm SD & $67.8 \pm 17.4$ & $60.3 \pm 17.9$ & $52.5 \pm 21.3$ & $44.9 \pm 19.4$ & $40.6 \pm 18.8$ & $<0.001$ \\
\hline I could contribute to medical progress. N (\%) & $147(42.0 \%)$ & $172(49.1 \%)$ & $23(6.6 \%)$ & $6(1.7 \%)$ & $2(0.6 \%)$ & \\
\hline Mean score \pm SD & $68.9 \pm 16.3$ & $57.4 \pm 18.3$ & $51.4 \pm 22.0$ & $45.8 \pm 19.7$ & $33.3 \pm 11.8$ & $<0.001$ \\
\hline I would be considered a "guinea pig." N (\%) & $34(9.8 \%)$ & $100(28.9 \%)$ & $100(28.9 \%)$ & $55(15.9 \%)$ & $57(16.5 \%)$ & \\
\hline Mean score \pm SD & $50.1 \pm 24.1$ & $56.4 \pm 18.0$ & $63.7 \pm 16.9$ & $62.5 \pm 15.4$ & $70.5 \pm 20.3$ & $<0.001$ \\
\hline I trust doctors. N (\%) & $83(23.2 \%)$ & $204(57.0 \%)$ & $40(11.2 \%)$ & $25(7.0 \%)$ & $6(1.7 \%)$ & \\
\hline Mean score \pm SD & $68.2 \pm 18.4$ & $60.7 \pm 17.0$ & $54.7 \pm 17.1$ & $51.7 \pm 23.8$ & $41.0 \pm 28.6$ & $<0.001$ \\
\hline $\begin{array}{l}\text { I am afraid of adverse events related to the } \\
\text { drug tested. } N(\%)\end{array}$ & $82(23.3 \%)$ & $155(44.0 \%)$ & $52(14.8 \%)$ & $47(13.4 \%)$ & $16(4.6 \%)$ & \\
\hline Mean score \pm SD & $48.5 \pm 20.8$ & $58.2 \pm 16.7$ & $70.1 \pm 16.5$ & $69.8 \pm 14.7$ & $72.6 \pm 26.9$ & $<0.001$ \\
\hline I could receive a more effective treatment. N (\%) & $62(18.7 \%)$ & $159(47.9 \%)$ & $57(17.2 \%)$ & $42(12.7 \%)$ & $12(3.6 \%)$ & \\
\hline Mean score \pm SD & $70.1 \pm 16.9$ & $62.7 \pm 16.1$ & $56.9 \pm 20.2$ & $53.8 \pm 18.5$ & $54.5 \pm 29.8$ & $<0.001$ \\
\hline I would respect my personal convictions. N (\%) & $84(25.5 \%)$ & $126(38.3 \%)$ & $100(30.4 \%)$ & $12(3.7 \%)$ & $7(2.1 \%)$ & \\
\hline Mean score \pm SD & $65.6 \pm 18.9$ & $62.8 \pm 15.7$ & $59.5 \pm 19.9$ & $49.7 \pm 19.2$ & $46.4 \pm 28.4$ & $<0.001$ \\
\hline I would be anxious about surgery. N (\%) & $60(17.0 \%)$ & $130(36.8 \%)$ & $68(19.3 \%)$ & $63(17.9 \%)$ & $32(9.1 \%)$ & \\
\hline Mean score $\pm S D$ & $52.4 \pm 24.1$ & $56.7 \pm 18.0$ & $64.2 \pm 16.8$ & $64.1 \pm 14.9$ & $76.5 \pm 18.0$ & $<0.001$ \\
\hline I would be worried about inefficacy of the drug tested. N (\%) & $48(14.1 \%)$ & $119(35.0 \%)$ & $73(21.5 \%)$ & $76(22.4 \%)$ & $24(7.1 \%)$ & \\
\hline Mean score $\pm S D$ & $47.9 \pm 25.3$ & $57.2 \pm 16.6$ & $61.6 \pm 16.5$ & $66.8 \pm 18.1$ & $80.5 \pm 17.3$ & $<0.001$ \\
\hline I think that research only benefits the doctor's career. N (\%) & $12(3.5 \%)$ & $29(8.3 \%)$ & $38(10.9 \%)$ & $125(35.9 \%)$ & $144(41.4 \%)$ & \\
\hline Mean score \pm SD & $38.9 \pm 29.0$ & $55.7 \pm 14.8$ & $57.0 \pm 12.9$ & $59.3 \pm 17.7$ & $65.9 \pm 19.5$ & $<0.001$ \\
\hline
\end{tabular}

*Cuzick test for trend

more specifically patients' personal concerns, were more likely to participate to a clinical trial [25]. A similar finding was reported in a pediatric study [43]. These findings emphasize that willingness to participate is strongly influenced by trust, confidence and the feeling of familiarity with the different aspects of study content, the latter of which is essential to guarantee informed consent [44]. The potential disincentive of full disclosure of risks can potentially be mediated by ensuring patients in the recruitment process are provided with individual attention by health care professionals that are willing and qualified to listen carefully to patient concerns and explain the details to a depth that satisfies the patient.

Another interesting finding in the present study is that the lack of fear about double-blinding was positive predicting factor for participation. This result agrees well with current literature reporting that specific procedures associated with trial design, such as randomization, the use of a placebo or double-blinding, are often poorly understood by patients and can become significant barriers to participation [45]. These findings emphasize again that patients must be provided the required information, including complex concepts such as double blinding, in a way that they can understand sufficiently for informed consent.

We also found that patients taking medication on a regular basis were more willing to participate. This may be explained by the fact that taking medication on a regular basis is a surrogate of having a chronic disease. As identified in the study, a majority of patients believe they can benefit from a better treatment when participating to a trial. It is quite likely that both items are correlated and that patients with chronic disease (taking medication on a regular basis) are more willing to participate because they believe they could benefit from a better treatment and recover from their disease.

A number of limitations of this study need to be mentioned. One is the use of a randomization process to identify on a list of discharged hospital patients, potential study participants. While this ensured a representative sample of in hospital patients likely to be enrolled in clinical trials, we were unable to fully identify before sending the questionnaires, patients who would obviously be unable to participate. This included deceased patients, those having language barriers hindering study participation and those unable to answer due to severe 
Table 5 Study-related factors and mean willingness-to-participate scores

\begin{tabular}{|c|c|c|c|c|c|c|}
\hline Study-related factors influencing the willingness to participate & Strongly agreed & Agreed & No opinion & Disagreed & $\begin{array}{l}\text { Strongly } \\
\text { disagreed }\end{array}$ & $\boldsymbol{P}$ value $^{*}$ \\
\hline $\begin{array}{l}\text { If you received financial compensation, would you be more } \\
\text { willing to participate? N (\%) }\end{array}$ & $55(14.9 \%)$ & $62(16.8 \%)$ & $70(18.9 \%)$ & $73(19.7 \%)$ & $110(29.7 \%)$ & \\
\hline Mean score \pm SD & $65.5 \pm 17.6$ & $62.2 \pm 15.8$ & $63.1 \pm 16.2$ & $56.2 \pm 18.8$ & $57.3 \pm 23.6$ & 0.006 \\
\hline $\begin{array}{l}\text { If participating in the study required commuting to the } \\
\text { hospital, would you decline to participate? N (\%) }\end{array}$ & $40(11.1 \%)$ & 79 (21.9\%) & $57(15.8 \%)$ & $111(30.8 \%)$ & $74(20.5 \%)$ & \\
\hline Mean score \pm SD & $48.3 \pm 25.2$ & $56.6 \pm 17.3$ & $60.8 \pm 17.8$ & $62.3 \pm 15.5$ & $69.1 \pm 19.6$ & $<0.001$ \\
\hline $\begin{array}{l}\text { If the study required blood tests, would you decline to } \\
\text { participate? N (\%) }\end{array}$ & $24(6.4 \%)$ & $46(12.3 \%)$ & $52(13.9 \%)$ & $110(29.4 \%)$ & $142(38.0 \%)$ & \\
\hline Mean score \pm SD & $44.3 \pm 21.5$ & $55.5 \pm 17.7$ & $55.4 \pm 19.2$ & $58.6 \pm 15.1$ & $68.2 \pm 19.1$ & $<0.001$ \\
\hline $\begin{array}{l}\text { If the study required randomly assigned treatment, } \\
\text { would you decline to participate? N (\%) }\end{array}$ & 95 (27.1\%) & 110 (31.4\%) & $42(12.0 \%)$ & $76(21.7 \%)$ & $27(7.7 \%)$ & \\
\hline Mean score \pm SD & $50.4 \pm 22.6$ & $58.6 \pm 15.2$ & $64.4 \pm 16.4$ & $66.1 \pm 16.4$ & $69.1 \pm 24.4$ & $<0.001$ \\
\hline $\begin{array}{l}\text { If the study required a treatment that was prescribed by the study } \\
\text { and not by your doctor, would you be willing to participate? } N(\%)\end{array}$ & 37 (10.4\%) & 143 (40.1\%) & $39(10.9 \%)$ & $84(23.5 \%)$ & $54(15.1 \%)$ & \\
\hline Mean score \pm SD & $71.1 \pm 21.6$ & $64.9 \pm 13.3$ & $59.5 \pm 15.5$ & $54.4 \pm 19.3$ & $48.4 \pm 26.5$ & $<0.001$ \\
\hline $\begin{array}{l}\text { If the study involved a placebo (inactive substance), would } \\
\text { you decline to participate? N (\%) }\end{array}$ & 40 (11.3\%) & 62 (17.5\%) & 65 (18.3\%) & $101(28.5 \%)$ & 87 (24.5\%) & \\
\hline Mean score \pm SD & $43.2 \pm 27.8$ & $56.7 \pm 18.0$ & $60.6 \pm 17.3$ & $61.2 \pm 15.9$ & $68.5 \pm 17.2$ & $<0.001$ \\
\hline $\begin{array}{l}\text { Many clinical trials are double-blind studies. This means that } \\
\text { neither doctors nor the participants are aware which participants } \\
\text { receive the test drug and which receive the placebo. Would you } \\
\text { consider this a reason to decline participation? N (\%) }\end{array}$ & $62(17.5 \%)$ & 95 (26.8\%) & 34 (9.6\%) & 82 (23.2\%) & 81 (22.9\%) & \\
\hline Mean score $\pm S D$ & $48.5 \pm 23.8$ & $54.5 \pm 16.6$ & $64.9 \pm 12.2$ & $64.8 \pm 16.0$ & $70.4 \pm 19.1$ & $<0.001$ \\
\hline
\end{tabular}

${ }^{*}$ Cuzick test for trend

disease. This resulted in a significant number of patients being approached $(N=482)$ who should have been excluded at study beginning. Despite these limitations, our population sampling presented a good cooperation rate (65\%) allowing significant and valid conclusions.

Another limitation is the non-participation of patients with severe health problems. As their willingness to participate could not be established, we are unable to draw valid conclusions on this category of patients regarding their willingness to participate to a trial in the area of anesthesia care. At the same time, we still included a significant number of participants (68.8\%) reporting regular use of medication for a chronic disease, tempering the non-participation of patients with severe health problems.

Another limitation is the use of hypothetical scenarios of anesthesia trials to assess willingness to participate. This methodological approach may increase the risk of information bias since a number of participants may not fully understand the exact content of the vignettes provided. This may distort their answers and their ability the reliably identify true differences between the different scenarios provided. However, clinical vignettes are common tools used in studies assessing patient perspective on the qualitative dimensions of medical practice and research. They

Table 6 Multivariable logistic-regression model predicting willingness to participate

\begin{tabular}{|c|c|c|c|}
\hline & $\begin{array}{l}\text { Willingness to participate in } \\
\text { a clinical trial } \\
\text { Beta coefficient }\end{array}$ & $\begin{array}{l}95 \% \\
\text { Confidence interval }\end{array}$ & $P$ value \\
\hline Intercept (alpha) & 30.2 & 13.3 to 47.1 & 0.001 \\
\hline I am afraid of adverse events related to the drug tested (yes/ no) & -11.7 & -16.9 to -6.5 & $<0.001$ \\
\hline I could help other patients. (yes/ no) & 9.6 & 3.4 to 15.7 & 0.002 \\
\hline $\begin{array}{l}\text { I would not consider double-blinding a reason to decline participation. } \\
\text { (yes/ no) }\end{array}$ & 5.7 & 1.3 to 10.2 & 0.012 \\
\hline I would be anxious about surgery. & -5.2 & -10.0 to -0.5 & 0.031 \\
\hline I could contribute to medical progress. (yes/ no) & 9.5 & 2.1 to 17.0 & 0.012 \\
\hline I could receive a more effective treatment. (yes/ no) & 4.7 & 0.2 to 9.2 & 0.041 \\
\hline
\end{tabular}


can significantly contribute to improve understanding of patient perceptions on these topics.

Finally, the questionnaire addressed issues that had for some of them, been previously identified as factors influencing willingness to participate in a clinical trial. In addition the exclusive use of closed-ended questions in our questionnaire allowed only quantitative assessment. As a result we could not identify the full range of possible barriers to clinical trial participation that a qualitative study would have allowed.

Despite these limitations, the present study provides valuable information about personal and study-related factors that influence patient willingness to participate to clinical trials in anesthesia care. While in any trial patients have to balance their willingness to participate according to a specific risk benefits ratio, knowing which factors are more likely to worry patients and ultimately lead to their refusal to participate may be very helpful. For instance, in a trial testing a new anesthetic drug, knowing patient's fear of side effects of the medication provided may help to better detail these side effects (without minimizing them) and as a result decrease patient's level of anxiety. In addition, explaining to patients the benefits of participation not only for them but also for the wider community may contribute to an enhanced level of participation in patients with altruistic values.

Therefore, we suggest that, to improve participation, researchers should ensure that required information is comprehensively explained to patients and that the important aspects of study participation are emphasized. The information should highlight personal and collective benefits resulting from the participation in a study, as well as clearly explaining the possible adverse effects of the treatment and thoroughly address patient concerns about any surgical intervention involved in the treatment. Information delivered to patients should be pertinent, understandable and address patients' concerns in a way that builds trust. Healthcare organizations recruiting participants to clinical trials should consider the development of practical handbooks that alert both researchers and patients to key factors influencing willingness to participate. Future research should assess in a prospective study new approaches to improve participation rates by providing targeted information strategies in face-to-face encounters and that address patient attitudes and fears.

\section{Conclusion}

The power of clinical trials can become compromised and costly when patient participation falls below expectations. Assessing different kind of hypothetical scenarios of clinical trials in anesthesia, the present study has identified a number of factors that may affect willingness to participate positively (altruism, benefits from a more effective treatment, absence of concerns about double blinding) and negatively (fear of adverse effects of the test drug, anxiety about surgery). It is hoped that, by taking these factors into consideration, clinical trial organizers can improve participation by providing required and appropriate information and reassurance to the patients.

\section{Supplementary information}

Supplementary information accompanies this paper at https://doi.org/10. 1186/s12874-020-00949-5.

Additional file 1. Questionnaire. Participation in a clinical trial in anesthesia: attitude, barriers and motivations of patients.

Abbreviations

SD: Standard Deviation; MWS: Mean Scores for Willingness-to-participate

\section{Acknowledgements}

The authors would like to thank Mrs. Claudine Carera and Mr. Patrick Huwiler for their invaluable help during the data collection process. We would also like to thank Prof. Walid Habre for his precious support and pertinent advice and comments on the final version of the manuscript.

\section{Authors' contributions}

$\mathrm{CN}, \mathrm{GH}, \mathrm{BG}, \mathrm{IP}$ contributed to the conception of study protocol, design of the work and acquisition of data..GH, CN, PB participated to the acquisition and interpretation of data for the work. All authors, CN, GH, BG, IP, PB have been involved in drafting the manuscript and revising its content. All authors, $\mathrm{CN}, \mathrm{GH}, \mathrm{BG}, \mathrm{IP}, \mathrm{PB}$ read and approved the final version of the manuscript to be published.

\section{Funding}

Institutional funding Geneva University Hospitals (departmental grant for research).

\section{Availability of data and materials}

The datasets generated and/or analysed during the current study are not publicly available due to absence of formal ethics approval for this, but are available from the corresponding author on reasonable request.

\section{Ethics approval and consent to participate}

Central Ethics Committee of Human Research of the Geneva University Hospitals, Switzerland (CER 12-123 - NAC 12-049). Waiver for explicit written individual consent granted.

\section{Consent for publication}

Not applicable.

\section{Competing interests}

The authors declare that they have no competing interests.

\section{Author details}

${ }^{1}$ Division of Anesthesia, Department of Acute Care Medicine, Geneva University Hospitals and Faculty of Medicine University of Geneva, Rue Perret-Gentil 4, Geneva, Switzerland. ${ }^{2}$ Clinical Research Center and Division of Clinical Epidemiology, Department of Health and Community Medicine, University of Geneva, University Hospitals of Geneva, Geneva, Switzerland. ${ }^{3}$ Health Services Management and Research Unit, Department of Epidemiology and Preventive Medicine, Monash University, The Alfred Centre, 99 Commercial Road, Melbourne Vic 3004, Australia. 
Received: 9 January 2019 Accepted: 6 March 2020

Published online: 19 March 2020

\section{References}

1. Myles PS, Bain DL, Johnson F, McMahon R. Is anaesthesia evidence-based? A survey of anaesthetic practice. Br J Anaesth. 1999;82(4):591-5.

2. Easterbrook PJ, Matthews DR. Fate of research studies. J R Soc Med. 1992; 85(2):71-6.

3. Henderson $M$, Addington-Hall JM, Hotopf $M$. The willingness of palliative care patients to participate in research. J Pain Symptom Manag. 2005;29(2): 116-8.

4. Cullati S, Counvoisier DS, Gayet-Ageron A, Haller G, Irion O, Agoritsas T, et al. Patient enrollment and logistical problems top the list of difficulties in clinica research: a cross-sectional survey. BMC Med Res Methodol. 2016;16:50.

5. McDonald AM, Knight RC, Campbell MK, Entwistle VA, Grant AM, Cook JA, et al. What influences recruitment to randomised controlled trials? A review of trials funded by two UK funding agencies. Trials. 2006;7:9.

6. Tournoux C, Katsahian S, Chevret S, Levy V. Factors influencing inclusion of patients with malignancies in clinical trials. Cancer. 2006;106(2):258-70

7. Mills E, Wilson K, Rachlis B, Griffith L, Wu P, Guyatt G, et al. Barriers to participation in HIV drug trials: a systematic review. Lancet Infect Dis. 2006; 6(1):32-8.

8. Cunny KA, Miller HW. Participation in clinical drug studies: motivations and barriers. Clin Ther. 1994:16(2):273-82.

9. Mills EJ, Seely D, Rachlis B, Griffith L, Wu P, Wilson K, et al. Barriers to participation in clinical trials of cancer: a meta-analysis and systematic review of patient-reported factors. Lancet Oncol. 2006;7(2):141-8.

10. Stead M, Eadie D, Gordon D, Angus K. "Hello, hello-it's English I speak!": a qualitative exploration of patients' understanding of the science of clinical trials. J Med Ethics. 2005;31(11):664-9.

11. Ross S, Grant A, Counsell C, Gillespie W, Russell I, Prescott R. Barriers to participation in randomised controlled trials: a systematic review. J Clin Epidemiol. 1999;52(12):1143-56.

12. Balajonda N, Bisanar TL, Mathew JP, Pang H, Voils Cl. Determinants of a subject's decision to participate in clinical anesthesia research. Anesth Analg. 2013;116(2):448-54.

13. Nguyen-Xuan HT, Thiollier G, Ruault O, Fauconnier A, Lucot JP, Bader G. Study of the factors motivating refusal of women to participate to a randomized clinical trial in gynecological surgery. Retrospective observational bicentric study. J Gynecol Obstet Biol Reprod (Paris). 2016 45(9):1054-9.

14. Joseph RR. Viewpoints and concerns of a clinical trial participant. Cancer 1994;74(Suppl 9):2692-3.

15. Mattson ME, Curb JD, McArdle R. Participation in a clinical trial: the patients' point of view. Control Clin Trials. 1985;6(2):156-67.

16. Ellis PM. Attitudes towards and participation in randomised clinical trials in oncology: a review of the literature. Ann Oncol. 2000;11(8):939-45.

17. Corbie-Smith G, Thomas SB, Williams MV, Moody-Ayers S. Attitudes and beliefs of African Americans toward participation in medical research. J Gen Intern Med. 1999;14(9):537-46.

18. Llewellyn-Thomas HA, McGreal MJ, Thiel EC, Fine S, Erlichman C. Patients' willingness to enter clinical trials: measuring the association with perceived benefit and preference for decision participation. Soc Sci Med. 1991;32(1): 35-42.

19. Agoritsas T, Deom M, Perneger TV. Study design attributes influenced patients' willingness to participate in clinical research: a randomized vignette-based study. J Clin Epidemiol. 2011;64(1):107-15.

20. Nguyen TT, Somkin CP, Ma Y. Participation of Asian-American women in cancer chemoprevention research: physician perspectives. Cancer. 2005; 104(Suppl 12):3006-14

21. Loh SY, Lee SY, Quek KF, Murray L. Barriers to participation in a randomized controlled trial of qigong exercises amongst cancer survivors: lessons learnt. Asian Pac J Cancer Prev. 2012;13(12):6337-42.

22. Kaur G, Hutchison I, Mehanna H, Williamson P, Shaw R, Tudur SC. Barriers to recruitment for surgical trials in head and neck oncology: a survey of trial investigators. BMJ Open. 2013;3:4

23. Sengupta S, Strauss RP, DeVellis R, Quinn SC, DeVellis B, Ware WB. Factors affecting African-American participation in AIDS research. J Acquir Immune Defic Syndr. 2000;24(3):275-84.
24. Zuniga ML, Blanco E, Martinez P, Strathdee SA, Gifford AL. Perceptions of barriers and facilitators to participation in clinical trials in HIV-positive Latinas: a pilot study. J Women's Health (Larchmt). 2007;16(9):1322-30.

25. Mingus ML, Levitan SA, Bradford CN, Eisenkraft JB. Surgical patients' attitudes regarding participation in clinical anesthesia research. Anesth Analg. 1996;82(2):332-7.

26. Brull R, McCartney CJ, Chan WW, Chung F, Rawson R. Are patients comfortable consenting to clinical anesthesia research trials on the day of surgery? Anesth Analg. 2004;98(4):1106-10.

27. Salomons TV, Wowk AA, Fanning A, Chan WW, Katz J. Factors associated with refusal to enter a clinical trial: epidural anesthesia is a deterrent to participation. Can J Anaesth. 2002;49(6):583-7.

28. van den Berg L, Lobatto RM, Zuurmond WW, de Lange JJ, Wagemans MF, Bezemer PD. Patients' refusal to participate in clinical research. Eur J Anaesthesiol. 1997:14(3):287-9.

29. Prescott RJ, Counsell CE, Gillespie WJ, Grant AM, Russell IT, Kiauka S, et al. Factors that limit the quality, number and progress of randomised controlled trials. Health Technol Assess. 1999;3(20):1-143.

30. Castel P, Negrier S, Boissel JP. Why don't cancer patients enter clinical trials? A review. Eur J Cancer. 2006:42(12):1744-8.

31. Verheggen FW, Nieman F, Jonkers R. Determinants of patient participation in clinical studies requiring informed consent: why patients enter a clinical trial. Patient Educ Couns. 1998;35(2):111-25.

32. Brintnall-Karabelas J, Sung S, Cadman ME, Squires C, Whorton K, Pao M. Improving recruitment in clinical trials: why eligible participants decline. J Empir Res Hum Res Ethics. 2011;6(1):69-74.

33. Roberson NL. Clinical trial participation. Viewpoints from racial/ethnic groups. Cancer. 1994;74(Suppl 9):2687-91.

34. Cox K, McGarry J. Why patients don't take part in cancer clinical trials: an overview of the literature. Eur J Cancer Care. 2003;12(2):114-22.

35. Wang LH, Tsai YF, Chen JS, Tsay PK. Intention, needs, and expectations of cancer patients participating in clinical trials. Cancer Nurs. 2011;34(2):117-23.

36. Lobato L, Bethony JM, Pereira FB, Grahek SL, Diemert D, Gazzinelli MF. Impact of gender on the decision to participate in a clinical trial: a crosssectional study. BMC Public Health. 2014;14:1156

37. Haski-Leventhal DMJ. Firefighters volunteering beyond their duty: an essential asset in rural communities. J Rural Commun Dev. 2009;2(4):80-92

38. McCann SK, Campbell MK, Entwistle VA. Reasons for participating in randomised controlled trials: conditional altruism and considerations for self. Trials. 2010;11:31.

39. Moorcraft SY, Marriott C, Peckitt C, Cunningham D, Chau I, Starling N, et al. Patients' willingness to participate in clinical trials and their views on aspects of cancer research: results of a prospective patient survey. Trials. 2016;17:17.

40. Treschan TA, Scheck T, Kober A, Fleischmann E, Birkenberg B, Petschnigg B, et al. The influence of protocol pain and risk on patients' willingness to consent for clinical studies: a randomized trial. Anesth Analg. 2003;96(2): 498-506.

41. Tait AR, Voepel-Lewis T, Siewert M, Malviya S. Factors that influence parents' decisions to consent to their child's participation in clinical anesthesia research. Anesth Analg. 1998;86(1):50-3.

42. Auszug aus dem Urteil der I. Zivilabteilung, Bundesgericht [1991] BGE 117 Ib 197.

43. Greenberg RG, Corneli A, Bradley J, Farley J, Jafri HS, Lin L, et al. Perceived barriers to pediatrician and family practitioner participation in pediatric clinical trials: findings from the clinical trials transformation initiative. Contemp Clin Trials Commun. 2018:9:7-12.

44. Townsley CA, Chan KK, Pond GR, Marquez C, Siu LL, Straus SE. Understanding the attitudes of the elderly towards enrolment into cancer clinical trials. BMC Cancer. 2006;6:34.

45. Chakrapani V, Newman PA, Singhal N, Jerajani J, Shunmugam M. Willingness to participate in HIV vaccine trials among men who have sex with men in Chennai and Mumbai, India: a social ecological approach. PLoS One $2012 \cdot 7(12) \cdot e 51080$.

\section{Publisher's Note}

Springer Nature remains neutral with regard to jurisdictional claims in published maps and institutional affiliations. 